\title{
An Ultimatum Wage Bargaining Experiment on Trade Union Efficiency
}

\author{
Adamos Andreou ${ }^{1}$ \\ Sofia Andreou ${ }^{2}$ \\ Aurora García-Gallego ${ }^{3}$ \\ Nikolaos Georgantzís ${ }^{4}$
}

\begin{abstract}
We present an ultimatum wage bargaining experiment showing that a trade union facilitating nonbinding communication among workers, raises wages by simultaneously increasing employers' posted offers and toughening the bargaining position of employees, without reducing overall market effic iency.
\end{abstract}

Keywords: Ultimatum Barga ining, Experiments, Trade Unions, Wages.

J日E: C 92, C 78, J 51, J 52.

\section{Introduction}

A widely accepted fact about trade unions (TUs) is that, by centralizing workers' bargaining strategies, they cause wages to rise. ${ }^{5}$ However, despite unionization, in many markets, decentralized bargaining takes place because individual workers aim at personal rather than collective objectives or due to lack of coordination among different TUs.

$1 \quad$ University of Cyprus, Economics Department, Cyprus; e-mail: adamosandreou@cytanet.com.cy. Tel: 00357 22892436, Fax: 0035722892432.

2 University of Cyprus, Ec onomics Department, Cyprus; e-mail: sofia@ucy.ac.cy. Tel: 00357 22892436, Fax: 0035722892432.

3 Universitat Jaume I and University of Cyprus, Economics Department, Cyprus; e-mail: aurorag@ucy.ac.cy. Tel: 00357 22892436, Fax: 0035722892432.

${ }^{4}$ Corresponding author. GLOBE \& Economics Dept., Universidad de Granada, Spain. email: ngeorgantzis@ugr.es. Tel: 00357 22892436, Fax: 0035722892432.

5 The trade unions with sufficient membership strength are able to barga in more effectively with the management than individual workmen (J ustice Ahmadi, in B.R. Singh v. Union of India). For a rigorous rent- sharing approach to wage determination under collective bargaining, see Christofides and Oswald (1992). 
In this context, a TU may have two opposite effects on market effic iency. First, by collectively setting a minimum acceptable wage, the $T U$ toughens workers' attitude in decentralized negotiations. In that case, ex post (after wage offers are observed) rejection of a broader range of low wages reduces worker partic ipation and market effic iency because some mutually benefic ial employeeemployer transactions do not take place. Second, the TU may cause employers' wage offers to rise in antic ipation to a tougher attitude by workers. The ex ante rise of employers' offers will tend to enhance worker participation and, thus, market efficiency. However, the overall effect resulting from the interplay of these two effects has not been addressed so far, probably because real-world data are not informative on the bargaining process preceding observed wages.

Labor market experiments offer infomation on both employees' and employers' strategies. Specifically, since its implementation in the seminal experiment by Güth et al. (1982), ultimatum bargaining constitutes a laboratory analogue of real-world transactions with take-it-or leave-it offers. While cheap talk messages from proposers to responders ${ }^{7}$ and vice versa ${ }^{8}$ have been studied in the context of ultimatum experiments, communication among respondents has not been studied so far. We undertake this task ${ }^{9}$, using the analogy between non binding communication among respondents and a cheap talk $\mathrm{TU}$ providing a coordination device for workers engaging in decentralized transactions.

\section{Experimental design and results}

The results reported here were obtained from three paper-and-pencil sessions with 90 subjects, recruited among economics students at the University of Cyprus. At the beginning of each session, subjects were randomly assigned the role of an employer or a worker. Common written instructions were distributed to them. ${ }^{10}$ They were not informed on the duration of the session. All sessions were stopped after period 15 . In each period, an employer writes a wage offer $X €$, which may be any amount between $0 €$ and $10 €$, in steps of $0.1 €$. A worker, who is randomly chosen to be matched ${ }^{11}$ with the employer in this period receives the offer and accepts or rejects it. In the case of acceptance, the worker eams X€ and the employer eams 10-X€. Otherwise, they both eam nothing. Subjects were paid

\footnotetext{
${ }^{6}$ On the use of labormarket experiments, see Falk and Fehr (2003).

7 Rankin (2003).

8 Andersson et al. (2008).

9 Beminghaus et al. (2003) experimentally compare collective and individual bargaining, considering collective players with perfect control over coordinated individuals' strategies. 10 Instructions translated from Greek and decision-feedback sheets are available upon request from the authors.

${ }^{11}$ Rand om employer-worker pairs were formed within 5 or 6 independent matching groups per session.
} 
according to their eamings in five periods which were randomly chosen at the end of the session, yield ing an average payment slightly below $17.5 €$ per subject.

In session $1^{12}$, which is used as the baseline, there was no $\mathrm{TU}$. Sessions $2^{13}$ and $3^{14}$ started in the same way as session 1 . However, before period 7 , subjects received new written instructions informing them that workers would exit the room and freely talk for 10 minutes. An experimentalist showed workers the way to another room which was isolated from the ma in session. Secrecy was guaranteed conceming the content of the communic ation among workers. In the meantime, another organizer made sure that no communication could take place among employers. After the union meeting ended, the experiment went on, keeping player roles and matching groups fixed.

Table 1 presents averages of proposed and accepted wages, eamings by subject type and the percentage of accepted offers. Overall, baseline offers approximately reproduce the usual $60 \%-40 \%$ split of the pie in favor of proposers. Thus, as pointed out in García-Gallego et al. (2008), the labor market framing adopted here produces similar results to those usually obtained from the abstract setup. ${ }^{15}$ From the information contained in the table, we state a number of results whic $h$ organize our sta tistic al a na lysis and disc ussion.

$\begin{array}{llllll} & \begin{array}{l}\text { Wage } \\ \text { offers }\end{array} & \text { Wages } & \begin{array}{l}\text { Employe } \\ \mathbf{r}\end{array} & \begin{array}{l}\text { Worker } \\ \text { eamings }\end{array} & \begin{array}{l}\text { eaming } \\ \mathbf{s}\end{array} \\ \begin{array}{lllll}\text { acceptanc } \\ \text { es }\end{array} \\ \text { Without TU } & 3.95 & 4.37 & 3.66 & 2.84 & 65 \% \\ \text { With TU } & 4.45 & 4.74 & 3.63 & 3.28 & 69 \% \\ \text { Overall sample } & 4.16 & 4.53 & 3.65 & 3.02 & 67 \%\end{array}$

Table 1: Averages of offers, wages and ea mings and acceptance frequencies.

RESULT1: The TU inc reases wage offers.

We check first whether the effect of the $\mathrm{TU}$ on employers' offers appears before or after employees' post-union reaction to past wage offers is observed.

1228 subjects in 4 matc hing groups of 4 and 2 groups of 6 subjects each.

1332 subjects, in 2 groups of 4 and 4 groups of 6 .

1430 subjects, in 5 groups of 6 subjects each.

15 A plethora of factors affecting behavior in ultimatum experiments, are discussed in Bearden's (2001) thorough review. 
That is, whether wage offers increase ex ante, because the $\mathrm{TU}$ affects employers' beliefs conceming workers' minimum acceptable wage, or whether employers raise their offers ex post, after having observed workers' post-union behavior. We compare matching group averages using a Wilcoxon test. In session 2 , there is a statistic a lly significant difference in offers a cross periods 6 and $7(p=0.03)$. In session 3 , there is no significant ex ante effect on employers' offers $(p=0.34)$. However, comparison between pre- and post-TU periods in session 3, shows that offers are signific antly higher in the presence of a TU than in the absence of it $(p=0.07)$. On the contrary, the exante reaction of employers to the union meeting in session 2 does not lead to a persistent increase of offers with respect to pre-union levels $(p=0.24$ ). Offers in periods 7-15 signific antly vary across sessions 1 and 2 (Mann Whitney, $p=0.05$ ), which also supports result 1 . In order to guarantee that the differences in offers across pre- and post-union sub-sessions are not due to other dynamics like for example leaming, we have also tested and rejected the existence of any similar differences across the corresponding sub-sessions in session $1 .{ }^{16}$

\section{RESULT2: The TU increases wages.}

Mostly, the tests performed here reproduce the pattems obta ined from the tests on result 1 . Spec ific ally, while wages in session 2 vary signific antly from period 6 to period $7(p=0.09)$, pooling together pre- and post- $T U$ data, yields no signific ant difference $(p=0.52)$. Similar to the results reported on wage offers, in session 3 , wages a re signific a ntly higher in periods 7-15 than in periods 1-6 $(p=0.07)$, whereas there is no difference between periods 6 and $7(p=0.68)$. Pooling together data from periods 7-15 in sessions 2 and 3, we find that wages in the presence of a $T U$ are signific antly higher than in the absence of it (Mann Whitney test, $p=0.04$ ). The lack of signific ant differences across sub-sessions 1-6 and 7-15 of session 1 shows that the wage differences across pre- and post-union sub-sessions should not be attributed to leaming or other dynamic s. ${ }^{17}$

\section{RESULT 3: The TU has a moderately positive effect on workers' eamings, leaving employers' eamings unaffected.}

We have tested for differences in workers' and employers' eamings across pre- and post-union periods. Apart from a subject's share of the pie from successful negotiations, this variable includes zero eamings due to rejected offers.

\footnotetext{
16 The significance of differences in offers across early (1-6) and late period (7-15) subsessions is rejected by a Wilcoxon test $(p=0.46)$. The significance of differences between periods 6 and 7 is also rejected $(p=0.60)$.

17 The significance of wage differences across periods 6 and 7 is rejected by a Wilcoxon test $(p=0.50)$. The signific ance of wage differences a cross early (1-6) and late period (7-15) sub-sessions is also rejected $(p=0.46)$.
} 
Taking matching group averages as independent observations and companing pre- and post-union data, we find that the $\mathrm{TU}$ does not significantly change employers' eamings (Mann Whitney test, $p=0.81$ ), whereas the increase in employees' eamings fails by a small marg in to pass the $10 \%$ signific ance threshold $(p=0.11)$.

\section{RESULT 4: The TU reduces workers' willingness to accept a given wage, whereas the percentage of accepted offers is moderately inc reased.}

The two parts of result 4 may seem to contra dict each other. However, an acceptance or rejection decision must be analyzed with respect to the wage offered in the first place. We do this by estimating a Probit model, in which the dependent variable takes the value 1 for acceptances and the value 0 for rejections. In table 2 , the significance of the union dummy coefficient $(p<0.05)$ implies that the $\mathrm{TU}$ reduces the probability of acceptance of a given offer. We find, also, that female workers are more likely to accept a given wage. Finally, session effects are non-significant. Interestingly, the negative effect of the union on acceptance probabilities does not translate into a lower percentage of overall acceptances. On the contrary, acceptancesmoderately rise from $65 \%$ to $69 \%$.

\begin{tabular}{llc} 
Acceptance & Coeff & $\begin{array}{c}\text { Standard } \\
\text { error }\end{array}$ \\
\hline Offer & $0.94^{* * *}$ & 0.08 \\
TU & $-0.35^{* *}$ & 0.14 \\
Female W & $0.50^{* * *}$ & 0.12 \\
S2 & 0.19 & 0.16 \\
S3 & -0.09 & 0.16 \\
Constant & $3.57^{* * *}$ & 0.35 \\
Pseudo R 2 & 0.245 &
\end{tabular}

Table 2: Probit results for the probability of an acceptance. Offer: wage offers, TU: dummy for data in the presence of a $\mathrm{TU}$, Female $\mathrm{W}$ : dummy taking the value 1 if the worker is female, S2, S3: dummies for session 2 and 3 data. Signific a nce: $*=10 \%, * *=5 \%, * *=1 \%$. 


\section{Conclusions}

We report results from a n ultimatum bargaining experiment showing that a cheap talk trade union facilitating verbal non binding communication among workers ra ises employers' wage offers and observed wages without causing any effic iency loss. In our experiment, the union increases wages by simultaneously raising employers' offers and employees' likelihood of rejecting them. The overall effect on market efficiency has been positive because, ex post, workers accepted a higher percentage of the offers they received.

\section{References}

Andersson, O., S. Kranz, E. Wengström, M. M. Galizzi and K. M. van der Wiel, 2008, Persuasion in Experimental Ultimatum Games, Otto-von-Guericke University Magdeburg, FEMM Working Paper 08020.

Bearden, J.N., 2001, Ultimatum Bargaining Experiments: The State of the Art, University of North Carolina, mimeo.

Beminghaus, S., W. Güth and C. Keser, 2003, Unity Suggests Strength: An Experimental Study of Decentralized and Collective Bargaining, Labour Ec onomic s, 10, 465-479.

Christofides, L and A. J. Oswald, 1992, Real Wage Determination and RentSharing in Collective Bargaining Agreements, Quarterly J oumal of Ec onomics, 107, 985-1002.

Falk, A. and E. Fehr, 2003, Why Labour Market Experiments, Labour Ec onomics, 10, 399-406.

García-Gallego, A., N. Georgantzís a nd A. J aramillo-Gutiérrez, 2008, Ultimatum Salary Bargaining with Real Effort, Ec onomic s Letters, 98, 78-83.

Güth, W., R. Schmittberger, and B. Schwarze, 1982, An Experimental Ana lysis of Ultimatum Bargaining, J oumal of Ec onomic Behavior and Organization, 3, 367-388.

Rankin, F. W., 2003, Communic ation in Ultimatum Games, Economics Letters, 81, 267-271. 